\title{
"NACER MUJER ES EL \\ MAYOR CASTIGO": SOBRE \\ LO FEMENINO EN LA CASA DE \\ BERNARDA ALBA DE FEDERICO GARCÍA LORCA
}

\author{
Anna Jamka \\ Universidad de Varsovia \\ https://doi.org/10.18778/8220-195-6.09
}

\section{Resumen}

¿Qué es ser mujer? ¿Se pueden sacar conclusiones vigentes acerca de la condición femenina sobre la base de una obra concebida en unas circunstancias completamente diferentes de las de ahora? Con el fin de responder a estas preguntas, en el presente estudio se analizarán tres protagonistas de La casa de Bernarda Alba de Federico García Lorca: María Josefa, Bernarda y Adela.

Las representantes de tres generaciones de mujeres -que han vivido y seguirán haciéndolo sin una autoridad masculina a la cual deberían corresponder- se estudiarán tomando en cuenta tanto su rol y lugar en la casa y en la dinámica familiar (abuela - madre - hija/hermana) como sus motivaciones y pasiones desde el punto de vista de la teoría de la dominación masculina de Pierre Bourdieu.

Palabras clave: García Lorca, Bourdieu, dominación masculina, feminismo. 


\section{1.}

\section{Introducción}

En febrero de 1934 Ernesto Pinto en su artículo sobre García Lorca escribió que:

De cada libro de Lorca, al menos para mí, como síntesis magnífica, queda una mujer. En cada verso - generalmente quemado por brasas interiores de pasión de hombre, se embellece con la sutil gracia de una imagen bien femenina. Leed «Canciones» $\mathrm{y}$ «Romancero gitano». ¿Qué sentís pasar? ¿Qué veis? (...) Y esa tendencia, más lucidamente aparece en el dramaturgo. Todo el teatro magnífico, extraordinario de García Lorca gira en torno de mujeres - que se hacen símbolos (Inglada, Fernández, 2017).

Aunque la cita sea anterior a la última obra del granadino, siendo el manuscrito de La casa de Bernarda Alba de 1936, nos parece que resume su trayectoria literaria de manera acertada. García Lorca fue, sin duda alguna, dramaturgo de mujeres. Basta recordar el desfile de personajes femeninos de sus piezas de teatro: Mariana Pineda, la Zapatera, la Novia de Bodas de sangre, la mujer estéril, Yerma o doña Rosita, la soltera. Aun así, La casa de Bernarda Alba es un caso especial en su producción dramática: es la única pieza del artista protagonizada por personajes exclusivamente femeninos. Más aún: el título de la misma indica inequívocamente la estrecha relación entre la trama y el universo femenino. El sintagma nominal se compone del núcleo 'casa' y el complemento de nombre 'de Bernarda Alba', lo cual es muy significativo ya que indica que la pieza no se centrará en la protagonista, sino más bien en un espacio físico determinado (Galán, 1989: 33). Sin embargo, el título apunta hacia la dominación de Bernarda: es la dueña de casa y, por consiguiente, ejerce el dominio sobre las relaciones que tienen lugar allí. El subtítulo -“drama de mujeres en pueblos de España”- es aún más sugerente puesto que indica que los hechos han de tener el carácter dramático y centrarse en la problemática de lo femenino (Galán, 1989: 33-35). De ahí, inferimos que lo 
femenino desempeña un papel primordial tanto en la trayectoria literaria del poeta como en la obra misma.

Asimismo, "en esta «casa de mujeres» andaluza no hay preocupación naturalista por la realidad; al contrario, se percibe la tendencia del drama poético a sintetizar, a mostrar un cierto orden, en el que se aplican leyes permanentes y cuya violación es desastrosa" (Aszyk, 1997: 115)1. El hecho de que La casa de Bernarda Alba esté fundamentada en una serie de oposiciones -tanto temáticas, espaciales y temporales como cromáticas- subraya aún más el carácter altamente simbólico y poético de la pieza. Hay que mencionar, además, que el universo dramático de Lorca está estructurado a base de dos polos opuestos: el principio de la autoridad y de la libertad (Josephs, Caballero, 1999). Cosa parecida sucede también en La casa de Bernarda Alba donde el gran supratema lorquiano -el conflicto entre la ley individual y la ley social- se realiza a través del enfrentamiento del autoritarismo (Bernarda) y el deseo de satisfacer sus propias necesidades (Adela y María Josefa) (Josephs, Caballero, 1999: 97). Llegados a este punto podemos suponer que los personajes del drama, tal y como hemos indicado al principio, también funcionan como símbolos.

Teniendo en cuenta lo dicho, i.e. la importancia de lo femenino y el carácter simbólico del drama, creemos que será de sumo interés analizar los tres personajes femeninos -Bernarda, María Josefa y Adela- desde el punto de vista de la teoría social de Pierre Bourdieu, haciendo hincapié en su teoría de la dominación masculina.

1 Todas las traducciones al español de las obras editadas en el polaco son de la autora del presente estudio, a no ser que se indique lo contrario. 


\section{La dominación masculina según Bourdieu}

Antes de proceder al análisis, cabe, sin embargo, comentar (de manera muy concisa y, en consecuencia, no exhaustiva) los conceptos básicos del sociólogo francés: el campo, el capital simbólico, el habitus, la doxa y el poder (la violencia) simbólica.

Según Bourdieu, el campo viene a ser un espacio social de acción, influencia y competencia, una red de relaciones objetivas entre agentes sociales que se definen por la posesión o producción de una forma específica de capital, propia del campo en cuestión (Fernández, Puente, 2009: 35). El concepto del capital, a su vez, abarca todos los bienes dignos de ser buscados en una formación social concreta (Fernández, Puente, 2009: 36). Aunque existan tantas formas de capital como campos, el capital simbólico no es un tipo más de capital, sino una forma de poder que no es percibida como tal (Fernández, 2005: 9). Como señala el sociólogo, "el capital simbólico es una propiedad cualquiera (...) que (...) se vuelve simbólicamente eficiente, como una verdadera fuerza mágica" (Bourdieu, 1999: 172-173). En suma, el capital simbólico es un poder reconocido, a la vez que desconocido, $y$, como tal, genera el poder simbólico y la violencia simbólica (Bourdieu, 1999: 197).

Un concepto indisolublemente ligado a los de campo y capital es el habitus: un sistema de disposiciones, esquemas de obrar, duraderas y transportables, adquiridas mediante experiencia práctica en el campo, es decir, conformadas e internalizadas en el individuo a través de la exposición a determinadas condiciones sociales (Dębska, 2015: 20). En suma, se trata de un sistema de percepción adquirido durante el proceso de socialización, un marco que orienta las elecciones de cada individuo (Dębska, 2015: 20). Por otro lado, la doxa es un conjunto de verdades incuestionables de una sociedad en particular. De ahí, una sociedad dóxica es aquella en la que el orden cosmológico y político establecido no se percibe como un orden posible, sino como un orden natural y evidente y, por tanto, incuestionable; en otras palabras, una sociedad dóxica es la que conoce perfectamente sus límites (Moi, 1991: 1026-1027). 
La relación de dominación -en términos de Bourdieu el poder simbólico (o la violencia simbólica)- es un poder legitimado e irreconocible que no revela su naturaleza y se lleva a cabo principalmente a través de los canales simbólicos de comunicación (por ejemplo, el lenguaje, el cuerpo y los sentimientos), y en consecuencia es indetectable e invisible para quienes lo sufren (Dębska, 2015: 22-23). La dominación masculina, según el sociólogo, es “el mejor ejemplo de aquella sumisión paradójica" ya que permite "entender la lógica de la dominación ejercida en nombre de un principio simbólico conocido y admitido tanto por el dominador como por el dominado" (Bourdieu, 2000:5). Veamos, a continuación, cómo los conceptos bourdieuanos se pueden aplicar al análisis de los personajes lorquianos.

\section{3.}

\section{La violencia simbólica en el universo lorquiano}

Para empezar, hemos de reiterar que la casa de Bernarda Alba es un espacio sin hombres: el padre está muerto y parece que las mujeres pueden funcionar lejos de la opresión y agresividad del patriarcado. Bernarda es la que posee el capital simbólico, es decir, es reconocida como la figura de autoridad por otras agentes en su campo (la casa); es ella quien tiene el derecho de hablar y de mandar. En consecuencia, es ella quien ejerce la violencia simbólica. No obstante, aunque sea dueña de la propiedad y "tirana de todos" 2 , la visión del mundo que transmite a sus hijas no es suya, sino que ha sido heredada y fortalecida a lo largo de los años en el proceso de socialización. En suma, es portavoz de la doxa.

Dicha visión, un esquema de obrar, de orientarse en el mundo, no es otra cosa que el habitus en términos de Bourdieu. Como resultado, el orden impuesto por Bernarda no es suyo.

2 Todas citas del drama lorquiano vienen de la 26/a edición de la obra, ed. Cátedra (1999). 
El confinamiento de las mujeres en el domicilio después de la muerte del patriarca es una práctica que se ha transmitido a través de la cultura y la tradición. La mujer justifica su decisión diciendo que "así pasó en casa de mi padre y en casa de mi abuelo". Por consiguiente, lo que valida los códigos de conducta social es la ley paterna.

La violencia simbólica se fundamenta en "la objetividad de las estructuras sociales y de las actividades productivas y reproductivas; se basa en una división sexual del trabajo de producción y reproducción biológico y social" (Bourdieu, 2000: 27) así como en el habitus que funciona como matriz del modo de pensar y obrar de todos los miembros de la sociedad (Moi, 1991). Las hijas de Bernarda se conforman con su destino, saben cómo actuar y cómo comportarse en este mundo en el que "hilo y aguja para las hembras. Látigo y mula para el varón”. Reconocen el carisma, el capital simbólico de Bernarda, no perciben la violencia simbólica que ejerce su madre (aunque sí que se dan cuenta de su violencia física) y han interiorizado el habitus: unas reglas inarticuladas que regulan la convivencia en el campo al ser guías para los agentes.

Otro punto es la motivación de la matriarca que no sólo confina físicamente a su propia familia, sino que lo hace porque no quiere traspasar los límites de una sociedad dóxica en la que las leyes y normas de conducta son naturales, evidentes e incuestionables. De ahí, se infiere que la función materna fortalece y reproduce la doxa: aunque tirana, Bernarda misma es una víctima de la violencia simbólica ejercida a lo largo de los años y parece que se ha convertido en portadora de la misma. No introduce una nueva ley, sino que transmite lealtad a un orden opresivo para su género. La violencia simbólica está inscrita en la doxa, en el orden natural del mundo, por lo que es una violencia amortiguada, silenciosa e invisible (Bourdieu, 2000: 5). Como la doxa, la violencia simbólica no se cuestiona, sino que se conserva: la perpetúan tanto los que la ejercen como los que la sufren.

Al mismo tiempo, Bernarda tiene la concepción tradicional de que la sexualidad femenina debe ser suprimida. En el funeral de su marido exclama que "Las mujeres en la iglesia no deben mirar más hombre que al oficiante, y a ése porque tiene faldas”. El 
deseo sexual femenino debe ser moderado a toda costa, y las que se rebelan, como Paca la Roseta o su hija Adela, han de ser castigadas. Conviene subrayar que cuando comentan que a Paca la Roseta se la llevó un grupo de hombres para mantener relaciones con ella, La Poncia advierte que esta mujer "no es de aquí. Es de muy lejos. Y los que fueron con ella son también hijos de forasteros. Los hombres de aquí no son capaces de eso". Otra vez podemos ver que la sociedad dóxica conoce muy bien sus límites y los que los traspasan son directamente rechazados, encasillados como 'foráneos'. Bernarda, en su doble calidad de víctima y verdugo, se ajusta a las expectativas patriarcales de una sociedad dóxica en la que los rasgos esenciales que constituyen el significado social de ser mujer en ese tiempo y en esa sociedad concreta se definían de forma precisa y cerrada, basándose en tres pilares fundamentales: amor, matrimonio y maternidad (Nieva-de la Paz, 2008: 156).

Como hemos indicado al principio, la paradoja de la doxa, es decir, el hecho de que el orden establecido se perpetúe con tanta facilidad, sin "transgresiones o subversiones, delitos y locuras" (Bourdieu, 2000: 5) se hace más evidente en el caso de "la dominación masculina, y en la manera como se ha impuesto y soportado" (Bourdieu, 2000: 5). Bernarda Alba es, por tanto, un ejemplo magistral de dicha paradoja, ya que por un lado es víctima de la sumisión simbólica, y por otro, la que ejerce y perpetúa la violencia simbólica. Cabe preguntarse si en la sociedad dóxica representada de manera poética y simbólica en La casa de Bernarda Alba hay alguien que pretenda salirse de los límites establecidos por la doxa.

Como hemos recalcado, las habitantes de la casa de Bernarda están sometidas a un orden en el que el significado social de mujer se construye a partir de su carácter como madre y esposa; la sexualidad femenina es tabú y debe ser reprimida bajo castigo. Dicha sumisión simbólica al orden represivo se manifiesta físicamente, ya que todas las mujeres están encerradas en el hogar. Además, el vehículo de la violencia simbólica es la matriarca. Aunque se pudiera suponer que las hijas desarrollarán la necesidad de liberarse, no es así. En palabras del sociólogo francés, "sus pensamientos y sus percepciones están estructurados de acuerdo 
con las propias estructuras de la relación de dominación que se les ha impuesto, sus actos de conocimiento son, inevitablemente, unos actos de reconocimiento, de sumisión" (26). Basta recordar las múltiples intervenciones donde las hijas muestran su conformidad con su destino ${ }^{3}$.

Ahora bien, hay dos personajes que parecen no resignarse al orden impuesto: Adela y María Josefa, la hija y la abuela. Queremos dejar claro que en caso de La casa de Bernarda Alba la liberación significa salir físicamente no solo de la casa, sino también del pueblo que forma parte de la sociedad dóxica, opresiva y patriarcal. Dicha convicción se revela en las múltiples intervenciones de las protagonistas que evocan el agua ya que la acción transcurre en un "maldito pueblo sin río, pueblo de pozos donde siempre se bebe el agua con el miedo de que esté envenenada". No obstante, las mujeres no solo asocian la libertad con la salida del pueblo, sino que también la buscan a través del hombre. De manera paradójica, el mismo orden patriarcal, la misma violencia simbólica que impone limitaciones a la agencia femenina, les proporciona la ilusión de libertad. En consecuencia, no se puede decir que la rebelión de Adela sea un intento de traspasar los límites de la sociedad dóxica. Su subversión contra la autoridad materna, el personaje que tiene el capital simbólico, no es un acto de liberación: al fin y al cabo, Adela confiesa que " ¡En mí no manda nadie más que Pepe!”. Todo esto parece confirmar que la hija ha interiorizado el habitus de su madre, aunque su manera de ser puede ser un poco diferente, ya que según Bourdieu:

estilo 'personal', es decir esa marca particular que llevan todos los productos de un mismo habitus, prácticas u obras, no es nunca otra cosa que una desviación con respecto al estilo propio de una época o de una clase, en la medida en que remite al estilo común no solamente por la conformidad (...) pero también por la diferencia que constituye la 'manera' (2007: 98).

3 Como p.ej. el diálogo entre Magdalena y su madre en el cual la hija constata que "Malditas sean las mujeres", o cuando Amelia afirma que "Nacer mujer es el mayor castigo". 
En consecuencia, aunque la actitud de Adela, el rechazo de la autoridad de Bernarda, a primera vista pueda parecer rechazo de los valores tradicionales, de la doxa, es, en realidad, la perpetuación de la misma.

El único personaje que percibe la violencia simbólica ejercida por Bernarda, que no ha interiorizado el habitus y se sale de las reglas establecidas por la sociedad dóxica es María Josefa, la abuela, una mujer envejecida que quiere casarse en la orilla del mar y tener hijos. Mientras Bernarda es la 'dominadora' y perpetúa la doxa, su madre es la voz de la disidencia, de herejía. Quiere actuar de acuerdo con sus propios anhelos en lugar de ajustarse a las expectativas de una sociedad dóxica en la que una mujer vieja no debería querer libertad, tener deseo sexual ni ansiar intimidad. Bernarda, sin embargo, no es capaz de entenderla. Al articular deseos personales que no se ajustan al orden establecido, María Josefa es considerada loca y encerrada por su hija. El hecho de que una mujer no se someta a la doxa, al orden simbólico, no es revolucionario, es una locura que merece castigo. Como hemos indicado, la anciana es la única que reconoce que su hija ejerce la violencia simbólica y, al hacerlo, mantiene el orden patriarcal. María Josefa es la única que ve en Pepe el Romano no el símbolo de la liberación, sino el de la dominación masculina: "es un gigante. Todas lo queréis. Pero él os va a devorar, porque vosotras sois granos de trigo. No granos de trigo, no. ¡Ranas sin lengua!”. Paradójicamente, la "loca" ve con más lucidez lo que las dos generaciones más jóvenes no son capaces de entender: su condición de sometidas a la dominación varonil.

\section{4. \\ Conclusiones}

Para concluir, se puede inferir de lo dicho, que el protagonista verdadero del drama es el orden simbólico, la doxa, la dominación masculina que se hace visible a través de los personajes femeninos: Bernarda en su doble calidad de víctima y ejecutora de 
la violencia simbólica; Adela, la que ha interiorizado el habitus de su madre y María Josefa como la voz de disidencia en una sociedad dóxica. Dicha interpretación de La casa de Bernarda Alba está en consonancia con su visión como un drama altamente simbólico, poético y universal en el que cada violación de las leyes establecidas conlleva consecuencias desastrosas, como en este caso, el suicidio de Adela.

Aunque según varios investigadores "Federico García Lorca plasma con eficaz rigor poético la situación de sus contemporáneas llevando a cabo en sus obras una revisión del funcionamiento social real de las claves de la identidad femenina en el período" (Nieva de la Paz, 2008: 375), hay que tener en cuenta el carácter altamente universal de la obra, tal y como el hecho de que se sigue estrenando en las escenas polacas. Su última puesta en escena se llevó a cabo a principios de 2018 en el Teatro Antiguo Helena Modrzejewska de Cracovia. El director, Alejandro Radawski, explicó que para él "paradójicamente, en este espectáculo, es la mujer la que se convierte en la herramienta de opresión contra otras mujeres, porque así es como se le enseñó" (Kościński, 2018). Como podemos ver, el protagonista principal, la dominación masculina, sigue siendo un referente actual ochenta y dos años después de la creación de la pieza.

\section{Bibliografía}

Aszyk, U. (1997). Federico García Lorca w teatrze swoich czasów. Warszawa: Energeia.

Bourdieu, P. (1980). El sentido práctico, trad. Ariel Dilon. Buenos Aires: Siglo XXI Editores, 2007.

Bourdieu, P. (1994). Razones prácticas. Sobre la teoría de la acción, trad. Thomas Kauf. Barcelona: Editorial Anagrama, 1997.

Bourdieu, P. (1998). La dominación masculina, trad. Joaquín Jordá. Barcelona: Editorial Anagrama, 2000.

Dębska, H. (2015). "Somatyzacja dominacji. Ciało w teorii socjologicznej Pierre’a Bourideu”. Studia Sociologica, VII/1, 18-38.

Fernández, J.M. (2005). "La noción de violencia simbólica en la obra de Pierre Bourdieu: una aproximación crítica”. Cuadernos de Trabajo Social, 18, 7-31. 
Fernández, J.M. y Puente Ferreras A. (2009). "La noción de campo en Kurt Lewin y Pierre Bourdieu: un análisis comparativo". Revista Española de Investigaciones Sociológicas, 127, 33-53.

Galán, E. (1989). Claves de La casa de Bernarda Alba. Federico García Lorca. Madrid: Ciclo Editorial.

García Lorca, F. (1999). La casa de Bernarda Alba. Madrid: Cátedra, ed. de Josephs A. y Caballero J.

García Lorca, F. (2017). Palabra de Lorca. Declaraciones y entrevistas completas, ed. de Inglada R. y Fernández V. Barcelona: Malpaso Ediciones.

Kościński, G. (2018). "Kraków. Premiera «Domu Bernardy Alba» F.G. Lorki w Starym Teatrze”, [en línea], <http://www.e-teatr. $\mathrm{pl} / \mathrm{pl} /$ artykuly/253520.html> [16.11.2018].

Moi, T. (1991). "Appropriating Bourdieu: Feminist Theory and Pierre Bourdieu's Sociology of Culture". New Literary History, 22/4, 1017-1049.

Nieva de la Paz, P. (2008). “Identidad femenina, maternidad y moral social: «Yerma» (1935). de Federico García Lorca”. Anales de la literatura española contemporánea, 33/2, 373-394. 